http://jmscr.igmpublication.org/home/ ISSN (e)-2347-176x ISSN (p) 2455-0450

crossref DOI: https://dx.doi.org/10.18535/jmscr/v9i12.07

\title{
Adverse effects of COVID-19 Vaccination (COVISHIELD) among Health Care Workers in a Tertiary Care Center in Northern India: An Observational Study
}

\author{
Authors \\ Dr Subhash Kashyap ${ }^{1}$, Dr Saru Thakur ${ }^{2 *}$, Dr Sucheta Pathania ${ }^{2}$, \\ Dr Anuja ${ }^{1}$, Dr Kapil Kumar ${ }^{3}$ \\ ${ }^{1}$ Assistant Professor, ${ }^{2}$ Senior Resident, ${ }^{3}$ Medical Officer \\ Department of Dermatology, Venereology and Leprosy, Shri Lal Bahadur Shastri Govt. Medical College, \\ Nerchowk, Distt. Mandi (H.P.) \\ *Corresponding Author

\section{Dr Saru Thakur}

Senior Resident, Department of Dermatology, Venereology and Leprosy, Shri Lal Bahadur Shastri Govt.

Medical College, Nerchowk, Distt. Mandi (H.P.), India

\begin{abstract}
COVID pandemic has brought the life to a standstill in all the nations of the world. Amidst which, covid vaccine appeared as a ray of hope.

Objective: To study the safety profile of the candidate vaccine and to assess the risk factors for development of side effects.

Materials and Methods: This is a hospital based prospective observational study in a tertiary care center in North India. All consecutive beneficiaries who got vaccinated at the vaccination site in the first phase were enrolled for the study. They were followed over a period of 3 months.

Results: This study included 1034 beneficiaries. The mean age group was $31.40 \pm 11.24$ years old. There were 612 females and 422 males. Adverse effects following immunization were seen in 784 (75.8\%) participants with systemic effects in 748 (72.3\%) and local adverse effects in $57.06 \%$ (590) of total participants. Pain at the injection site was the commonest local and fever was the commonest systemic side effect seen. Most of the systemic symptoms resolved in 1-2 days and few persisted for 5-7 days. Maximum side effects were observed in the age group of 21-30 years. The participants reporting side effects were significantly younger in age and were observed more frequently in females. Presence of co-morbidities was not associated with significantly higher incidence of adverse effects.

Conclusion: ChAdOx 1 nCov-19 corona virus vaccine (Recombinant) being used in mass campaign in our country has minor side effects and almost all usually resolve within a week. Presence of comorbidities does not confer any significantly higher risk of developing adverse effects following immunization.
\end{abstract}

Keywords: AEFI, covid-19 vaccination, health care workers, risk factors.

\section{Introduction}

Corona virus disease 2019 (COVID-19) is an infectious disease involving multiple systems predominantly the respiratory system. It is caused by severe acute respiratory syndrome corona virus 2 (SARS-CoV-2), which is a single stranded RNA virus. The first case of this disease was reported in December 2019 in Wuhan, Hubei province, 
China. It spread rapidly throughout the globe and hence was declared a pandemic in March 2020. Human to human transmission was confirmed even in asymptomatic carriers ${ }^{[1]}$. As of $11^{\text {th }}$ October 2021, this disease has infected more than 23,71,96,253 people worldwide and has caused $48,40,189$ deaths globally ${ }^{[2]}$. Finding a vaccine to curb the spread of this disease was a major challenge in 2020. As many as 174 vaccines were in pre-clinical development and 63 vaccines in clinical development ${ }^{[3]}$. In India, emergency use authorization was given initially to two indigenous vaccines - covishield and covaxin.

COVID-19 vaccine was introduced in a phased manner in our country starting from $16^{\text {th }}$ January 2021. Phase-1 started with the vaccination of the health care providers and workers in health care settings (Public and Private), including ICDS workers. The vaccine being used in Himachal Pradesh was covishield, made by the Serum Institute of India. Covishield is ChAdOx $1 \mathrm{nCov-}$ 19 corona virus vaccine (Recombinant).

\section{Objective}

To study the safety profile of the candidate vaccine among healthcare workers $(\mathrm{HCW})$ by recording related adverse effects following immunization (AEFI) and to assess the risk factors for development of side effects.

\section{Methodology}

This hospital based prospective observational study was conducted in the covid vaccination site at Shri Lal Bahadur Shastri Government Medical College, Ner Chowk, which is tertiary care health center to manage all serious potential complications. All consecutive beneficiaries who got vaccinated in the first phase were enrolled for the study. Written and informed consent was taken before starting the study. All the beneficiaries were observed for a period of 30 minutes following vaccination for any immediate reactions in the observation room. They were counseled and asked to report telephonically for any AEFI that appeared, which were recorded. A pre structured proforma was used to record all the AEFI on the visit for the second dose 4 to 6 weeks later. The AEFI observed post second dose were enquired telephonically.

The participants were instructed to monitor temperature themselves or from nearest health care facility in case of fever. Temperature $>37.4^{\circ} \mathrm{C}$ was considered as fever. Subjective symptoms like headache, malaise, myalgia, dizziness, nausea and abdominal pain etc. were considered significant, if they were severe enough to seek medical attention or were interfering with daily activities.

Inclusion Criteria: (1) Willing to participate in the study. (2) Age more than 17 years.

Exclusion Criteria: (1) History of allergic reactions in the past. (2) Not willing to participate in the study. (3) History of receiving any other vaccine in past 2 weeks.

\section{Data Analysis}

Data was entered in Excel spread sheet and accuracy of data entered was crosschecked, any wrong entries found were corrected. Categorial variable and continuous variable were reported as absolute frequency and relative frequency and mean \pm SD respectively and/or median and interquartile range for not normally distributed continuous variables. The difference between those with side effects and without side effects, of continuous variables and categorial variables wasanalysed using unpaired T-test and chi-square test respectively. Data wasanalysed by using Epiinfo version 3.5.2. $\mathrm{P}$ value of $<0.05$ was taken as statistically significant.

\section{Results}

A total of 1400 beneficiaries were vaccinated at our center. All had received 2 doses of the vaccine at the time of filling the proformas. Out of total beneficiaries, three participants had history of vaccination in past two weeks, hence were excluded based on our exclusion criteria. A total of 1034 beneficiaries had filled the proformas completely and were included in the final analysis. The rest were excluded as they conveyed 


\section{JMSCR Vol||09||Issue||12||Page 41-46||December}

incomplete information. The mean age group of our participants was $31.40 \pm 11.24$ years old. The youngest participant was 17 years old and the oldest one was 68 years of age. Among the participants, $612(59.2 \%)$. were females and 422 (40.8\%) were males.

AEFI were observed in $75.8 \%$ (784/1034)of total participants. Systemic AEFI were seen in $72.3 \%$
(748/1034) beneficiaries and local in $57.06 \%$ (590) of 1034 beneficiaries. The most commonly reported systemic side-effect was fever followed by fatigue. Among the total AEFI reported, 509 participants were females and 275 males. Maximum AEFI were reported in the age group of 21-30 years (Figure 1).

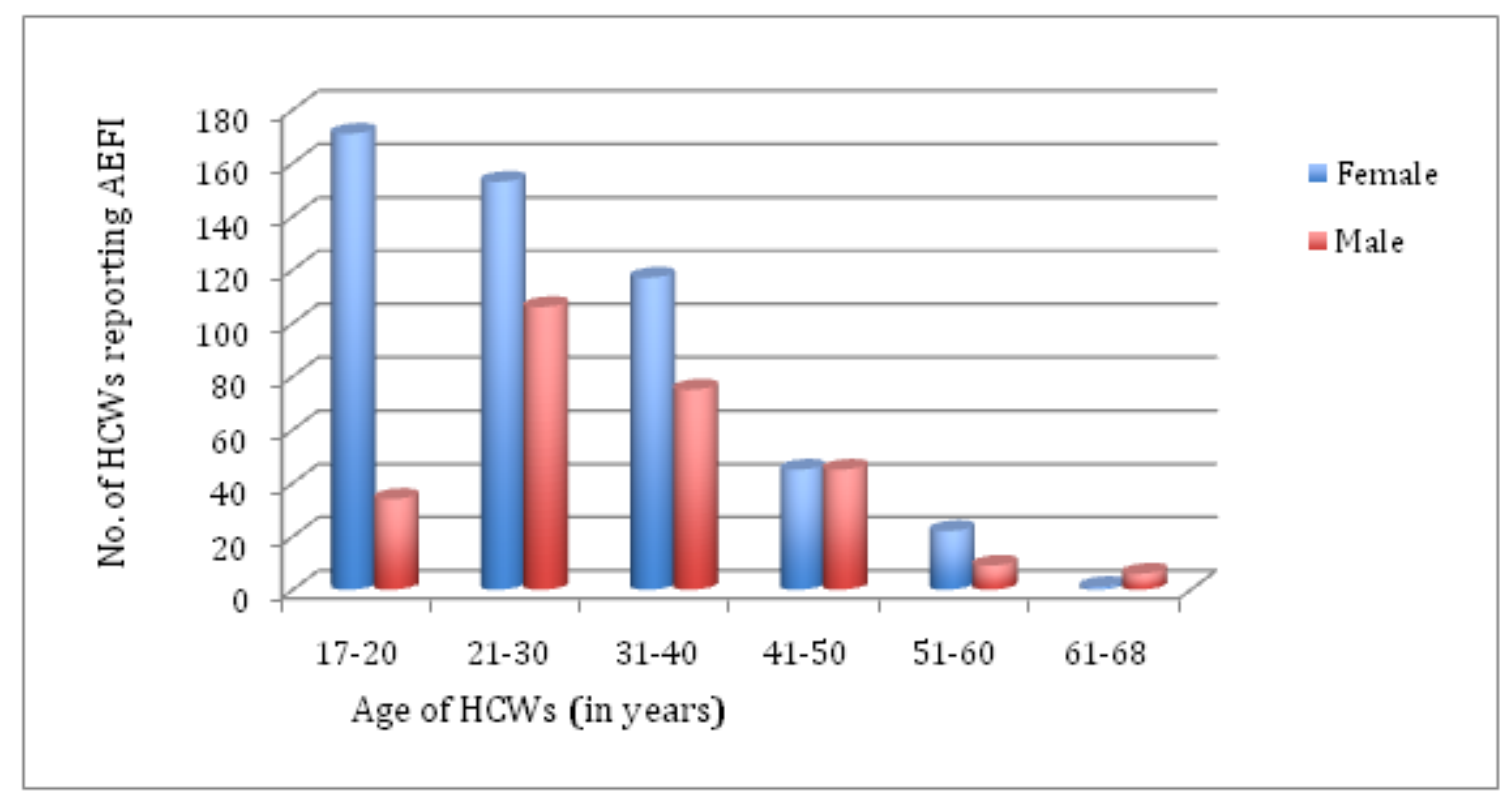

Figure 1: Age and gender distribution of participants with AEFI

\section{Local Symptoms}

Pain at the injection site was the commonest local symptom seen in $55.6 \%$ of the total beneficiaries and constituted $76.8 \%$ of the total AEFI (Table 1). This symptom first appeared within 8 hours of injection in 442 (76.9\%) people while $100(17.4 \%)$ beneficiaries developed pain within 8-24 hours of injection and $6(1.1 \%)$ developed after 24 hours of injection. These symptoms resolved within 8 hours in $8(1.4 \%)$, within 8-24 hours in 293 (51\%), 24-48 hours in 138 (24\%) and in 2-3 days in $132(23 \%)$ beneficiaries.

Dermatological side effects like rash, itching were seen in $1.5 \%$ cases each. Urticaria was seen in 1 participant and diffuse hair loss in 3 cases.

Table 1: Local site reactions observed

\begin{tabular}{|lccc}
\hline & $\begin{array}{c}\text { No. } \\
\text { reported }\end{array}$ & $\begin{array}{c}\text { Percentage of local } \\
\text { symptoms }\end{array}$ & $\begin{array}{c}\text { Percentage } \\
(\%)\end{array}$ \\
\hline LOCAL SITE REACTIONS : & 590 & 100 & 57.1 \\
\hline Swelling & 575 & 97.5 & 55.6 \\
\hline Itching & 99 & 16.8 & 9.6 \\
Rash & 16 & 2.7 & 1.5 \\
Bruising & 16 & 2.7 & 1.5 \\
Warmth & 11 & 1.9 & 1.1 \\
\hline Lump & 101 & 17.1 & 9.8 \\
Abscess & 0 & 0 & 0 \\
\hline Ulceration & 0 & 0 & 0 \\
\hline Enlarged local lymph nodes & 0 & 0 & 0 \\
\hline
\end{tabular}




\section{Systemic Symptoms}

The most frequently reported systemic symptom was fever. It was recorded within 8 hours in 352 (73.9\% of total fever cases), 8-24 hours in 99 (20.8\%) and after 24 hours in 25 (5.3\%) beneficiaries. Fever settled in 1 day in 245 (51.5\%), in 48 hours in $111(23.3 \%)$, in 72 hours in $96(20.2 \%)$ and in 96 hours in 24 (5.1\%). Most of the systemic symptoms resolved in 1-2 days and few persisted for 5-7 days.

Previously undocumented symptoms like vertigo, which persisted for one week was reported in one beneficiary. One beneficiary had shooting pain at interscapular area for 2-3 minutes over duration of 3 days. Three beneficiaries reported diffuse hair loss persisting for more than 3 months

Table 2 Systemic features observed among the HCWs

\begin{tabular}{|c|c|c|c|}
\hline & $\begin{array}{l}\text { No. of } \\
\text { HCW }\end{array}$ & $\begin{array}{l}\text { Percentage } \\
\text { of systemic } \\
\text { features } \\
(\%)\end{array}$ & $\begin{array}{c}\text { Percentage } \\
\text { of total } \\
\text { HCW } \\
\text { vaccinated } \\
(\%)\end{array}$ \\
\hline SYSTEMIC FEATURES : & 748 & 100 & 72.3 \\
\hline Light headedness & 167 & 22.3 & 16.2 \\
\hline Fever $(>37.4)$ & 476 & 63.6 & 46 \\
\hline Feverish feeling & 321 & 42.9 & 31 \\
\hline Chills & 240 & 32.1 & 23.2 \\
\hline Headache & 232 & 31.01 & 22.5 \\
\hline Feeling sick & 214 & 28.6 & 20.7 \\
\hline Joint pain & 173 & 23.1 & 16.7 \\
\hline Muscle pain & 278 & 37.2 & 26.9 \\
\hline Fatigue / lethargy & 407 & 54.4 & 39.4 \\
\hline Nausea & 85 & 11.4 & 8.2 \\
\hline Vomiting & 9 & 1.2 & 0.9 \\
\hline Diarrhoea & 9 & 1.2 & 0.9 \\
\hline Decreased appetite & 53 & 7.1 & 5.1 \\
\hline Abdominal pain & 15 & 2.0 & 1.5 \\
\hline Feeling dizzy & 107 & 14.3 & 10.3 \\
\hline $\begin{array}{l}\text { Flu like symptoms (sore throat, } \\
\text { high temp, cough, chills, running } \\
\text { nose) }\end{array}$ & 63 & 8.4 & 6.1 \\
\hline Excessive sweating & 62 & 8.2 & 6 \\
\hline Others & 5 & & \\
\hline
\end{tabular}

\section{Risk Determinants}

Participants with AEFI were younger with mean age of $29.49 \pm 10.61$ years as compared to those without AEFI (Table 3) and P. value was < 0.05 . More adverse effects were seen in females as compared to males. Out of 612 females included in this study, 509 reported an AEFI whereas, 275 males out of 422 reported AEFI. The male to female ratio of the study population is $1: 1.45$ whereas this ratio is $1: 1.85$ for development of AEFI and the difference was found to be statistically significant.

The incidence of AEFI was more in those who were infected with corona virus previously $(12 \%$ vs $8 \%$ ), however the difference was not statistically significant. There was no difference in presence of positive antibody titers for covid infection between the two groups. The presence of other comorbidities like hypertension (3.4\%), cardiac disease $(12.7 \%)$, diabetes $(1.8 \%)$, renal disease $(0.3 \%)$ and presence of previous drug allergies $(0.3 \%)$ had no effect on appearance of AEFI among the beneficiaries. 
Table 3 Risk determinants of beneficiaries with AEFI

\begin{tabular}{|c|c|c|c|c|}
\hline & $\begin{array}{c}\text { Patient with AEFI } \\
(n=784)\end{array}$ & $\begin{array}{c}\text { Patient without AEFI } \\
(n=250)\end{array}$ & Odds Ratio & P Value \\
\hline Age & $29.49 \pm 10.61$ (years) & $37.40 \pm 11.03($ years $)$ & - & $0.000 *($ ANOVA $)$ \\
\hline \multirow[t]{2}{*}{ Gender } & $509(83.2 \%)$ & $147(58.8 \%)$ & $0.37(0.28-0.51)$ & \multirow[b]{2}{*}{$0.000 *$} \\
\hline & $275(65.2 \%)$ & $103(41.2 \%)$ & $0.37(0.28-0.51)$ & \\
\hline Covid positivity prior to vaccination & $94(12 \%)$ & $20(8 \%)$ & $1.56(0.96-2.65)$ & 0.05 \\
\hline Positive Antibody status & $2(0.3 \%)$ & $2(0.8 \%)$ & $0.31(0.03-3.06)$ & 0.15 \\
\hline History of hypertension & $27(3.4 \%)$ & $12(4.8 \%)$ & $0.70(0.35-1.47)$ & 0.17 \\
\hline History of cardiac disease & $10(12.7 \%)$ & $1(0.4 \%)$ & $3.21(0.54-70.78)$ & 0.21 \\
\hline History of diabetes & $14(1.8 \%)$ & $7(2.8 \%)$ & $0.63(0.25-1.69)$ & 0.17 \\
\hline History of renal disease & $2(0.3 \%)$ & $\mathbf{0}$ & Undefined & 0.57 \\
\hline History of previous drug allergy & $2(0.3 \%)$ & $\mathbf{0}$ & Undefined & 0.57 \\
\hline History of neurological disorder & $\mathbf{0}$ & $\mathbf{0}$ & Undefined & - \\
\hline
\end{tabular}

\section{Discussion}

A vaccine against the pandemic that claimed more than 4 million lives and drained countries financially has been finally introduced and is being used in mass campaign. The vaccine's side effects can be categorized as either local or systemic reactions, and their severity varied from mild to moderate ${ }^{[4]}$.

The very common side effects of this vaccine are local site reactions, feeling unwell, fatigue, feverish feeling, headache, chills, nausea and myalgias. Uncommon side effects like dizziness, decreased appetite, pain abdomen, enlarged lymph nodes may be seen ${ }^{[5]}$. However, some of the side effects of this new vaccine may still be unknown and may appear over a period of time.

The mean age group of our participants was 31.40 \pm 11.24 years old as compared to $42.56 \pm 10.5$ years old in another study. Our youngest participant was 17 years old and the oldest one was 68 years of age as compared to 19 and 78 years in another study. There was female preponderance of AEFI in the present study $(59.2 \%)$ as also seen in $88.5 \%$ in another study ${ }^{[6]}$. In the present study, the adverse effects following vaccination were observed in $75.8 \%$ participants as compared to $93.1 \%$ in another study on health care workers in a foreign country ${ }^{[6]}$. Increased incidence of adverse effects may be attributed to increased number of female participants in the latter study. Most of the AEFI are subjective and hence may have gender-based differences in their perception $^{[7]}$.

The prevalence of side effects was slightly higher in the $\leq 43$-year-old group (94.8\%) in a study by Riad et al ${ }^{[6]}$. The present study also supports the higher incidence of adverse effects among younger age group as participants with AEFI had a mean of 29.49 years versus 37.40 in those without AEFI.

Individuals with evidence of past SARS-CoV-2 infection were more likely to have adverse effects than those without evidence of past infection as seen in a large-scale study ${ }^{[8]}$. This finding was supported by the present study also (12\% versus $8 \%$ ), however, not supported by statistical significance. This is supported by the finding that people with past infections have increased immunogenicity and higher antibody titers than those without previous infection ${ }^{[8,9]}$.

Injection site pain was the commonest AEFI seen in the present study as seen in previous studies followed by fever, fatigue, feverish feeling, muscle pains and chills. Rare AEFI like transverse myelitis and hemolytic anemia have been reported $^{[10]}$. None of these were reported in the present study. However, vertigo was seen in one patient, scapular pain in another and diffuse hair loss in 3 patients. Hair loss persisted for the total duration of the study period.

Among all the participants, $24.2 \%$ did not develop any AEFI, whereas the rest $75.8 \%$ reported one or more side effect. When these two groups were compared, it was seen that age and gender appeared to be significant factors determining the occurrence of AEFI. The presence of comorbidities did not confer any increased risk of developing AEFI. 


\section{Conclusion}

Covishield (ChAdOx 1 nCov-19 corona virus vaccine - Recombinant) is a safe vaccine. Minor local or systemic side effects can occur in threefourth of the vaccine recipients. However, most of them resolve within 2-4 days. Females and younger age group are more prone to develop side effects following vaccination. Presence of comorbidities or previous COVID infection does not confer an increased risk of developing adverse effects.

\section{Sources of Support: Nil}

\section{Bibliography}

1. Helmy YA, Fawzy M, Elaswad A, Sobieh A, Kenney SP, Shehata AA. The COVID19 pandemic: a comprehensive review of taxonomy, genetics, epidemiology, diagnosis, treatment, and control. J Clin Med

2020;9:1225. https://doi.org/10.3390/jcm9041225

2. World Health Organization. WHO coronavirus disease (COVID-19) dashboard. Accessed August 2, 2021. https://covid19.who.int/

3. World Health Organization. Draft landscape of COVID-19 candidate vaccines. Accessed January 29, 2021. https://www.who.int/publications/m/item/ draft-landscape-of-covid-19-candidatevaccines

4. Oliver, S.E.; Gargano, J.W.; Marin, M.; Wallace, M.; Curran, K.G.; Chamber land, M.; McClung, N.; Campos-Outcalt, D.; Morgan, R.L.; Mbaeyi, S.; et al. The Advisory Committeeon Immunization Practices' Interim Recommendation for Use of Pfizer-BioNTech COVID-19 Vaccine-United States, December 2020. Morb. Mortal. Wkly. Rep. 2020, 69, 19221924. [CrossRef]

5. Serum institute of India Pvt. Ltd.(2021). Covishield: ChAdOx1 nCov-19 Corona Virus Vaccine (Recombinant) [package insert].

Pune,

India.

https://www.google.com/url?sa=t\&source =web\&rct=j\&url=https://www.seruminstit ute.com/pdf/covishield_fact_sheet.pdf\&ve $\mathrm{d}=2 \mathrm{ahUKEwj}$ -

2tfzrMPuAhVX9nMBHYORB_8QFjAAe gQIARAB\&usg=AOvVaw1sNNRCTp9IBrRasYtv7gl

6. Riad, A.; Pokorná, A.; Attia, S.; Klugarová, J.; Košc ‘́ḱ, M.; Klugar, M. Prevalence of COVID-19 Vaccine Side Effects among Healthcare Workers in the Czech Republic. J. Clin. Med. 2021, 10,1428. https://doi.org/

\subsection{0/jcm 10071428}

7. Fillingim RB, Christopher CD, RibeiroDasilva MC, Rahim- WilliamsB, Riley IIIJL. Sex, Gender, and Pain: A Review of Recent Clinical and Experimental Findings. J Pain. 2009 May; 10(5): 447485. doi:10.1016/j.jpain.2008.12.001.

8. Menni C, Klaser K, May A, Polidori L, Capdevila J, Louca P, et al. Vaccine sideeffects and SARS-CoV-2 infection after vaccination in users of the COVID Symptom Study app in the UK: a prospective observational study. Lancet Infect Dis. 2021; 21: 939-49. https://doi.org/10.1016/ S14733099(21)00224-3

9. Krammer F, Srivastava K, Simon V. Robust spike antibody responses and increased reactogenicity in seropositive individuals after a single dose of SARSCoV-2 mRNA vaccine. medRxiv 2021; published online Feb 1 . https://doi.org/10.1101/2021.01.29.212506 53 (preprint).

10. Voysey M, Clemens SAC et al. Safety and efficacy of ChAdOx1 nCov-19 vaccine (AZD1222) against SARS-CoV-2: an interim analysis of four randomized controlled trials in Brazil, South Africa, and the UK. Lancet.2021; 397(10269): 98. 